\title{
Characterization of Different Electrolyte Composition Lithium Thionyl Chloride Reserve Battery by Electrochemical Impedance Spectroscopy
}

\author{
Mohammed Ahmed Zabara, ${ }^{1}$ (i) Hasan Göçmez, ${ }^{2,3}$ Akın Karabatak, ${ }^{2}$ and Burak Ulgut ${ }^{1, z}$ (i) \\ ${ }^{1}$ Department of Chemistry, Bilkent University, Ankara, Turkey \\ ${ }^{2}$ PILTEK Energy Systems Co., Ostim Science Park, Yenimahalle, Ankara, Turkey \\ ${ }^{3}$ Department of Metallurgy and Materials Engineering, Dumlupinar University, Kutahya, Turkey
}

\begin{abstract}
Electrochemical Impedance Spectroscopy (EIS) characterization for electrochemical processes in Lithium Thionyl Chloride reserve primary battery is shown. Two different electrolyte compositions are used to distinguish the changes in the EIS response. Galvanostatic EIS at discharge technique is used to obtain Kramers-Kronig compatible data for the reserve primary battery. The EIS data is analyzed by means of Equivalent Circuit models. The analysis shows the presence of five time-constants belonging to the electrochemical processes at Lithium anode, Solid Electrolyte Interface and the porous Carbon cathode. The change in the electrolyte composition causes the variation in the Solid Electrolyte Interface configuration and the kinetics of the $\mathrm{Li}$ anode processes. No variation in the cathode electrochemical processes observed by changing the electrolyte. The obtained results show the power of the non-destructive and in situ EIS technique to reveal the parameters for the electrochemical processes inside energy storage systems.

(c) 2021 The Electrochemical Society (“ECS”). Published on behalf of ECS by IOP Publishing Limited. [DOI: 10.1149/1945-7111/ abff61]
\end{abstract}

Manuscript submitted January 25, 2021; revised manuscript received February 24, 2021. Published May 19, 2021.

Electrochemical Impedance Spectroscopy (EIS) is employed routinely in the characterization of electrochemical storage devices. It is non-destructive, in situ and it elucidates the electrochemical processes at wide range of time scales. For example, in batteries it is used to study the charge transfer and the mass transport processes at anodes, cathodes and the formed interfaces. It provides data which is used to develop the materials and incorporate the features and effects of the interfaces. ${ }^{1,2}$

Like any characterization technique, EIS demands certain conditions for proper implementation. Linearity, stability and causality have to be maintained for correct interpretations of the characterized system. ${ }^{1,3}$ These conditions can be met by excitation using correct parameters under suitable conditions. For instance, linearity is achieved in electrochemical storage systems, which are non-linear in nature, through excitations with small amplitudes. Likewise, stability is obtained by performing the EIS experiment in time scales and excitation signals that do not change the state of the system. To test for the linearity, stability and causality of the obtained EIS data KramersKronig compatibility is applied. Deviations from the Kramers-Kronig compatibility identifies the disruption in any of the conditions. ${ }^{4,5}$

EIS for any electrochemical system is achieved by excitation with alternating voltage or current signals and measuring the resulting response. For batteries the excitation is typically done around the open circuit potential of the cell which results in applying positive and negative amplitudes which are effectively charge and discharge operations. This technique is applicable for reversible systems such as secondary batteries and capacitors but not for irreversible ones such as primary batteries and fuel cells. For the latter, excitation should be done around negative offsets which do not allow the signal to cross over to charging signals as shown in Fig. $1{ }^{6}$ It is also worth noticing that the excitation is applied in Galvanostatic mode, in which the excitation signal is a current signal and the response is measured as voltage.

Using Galvanostatic-EIS at discharge, we have shown in a previous study that linear and stable impedance data of Lithium Thionyl Chloride $\left(\mathrm{LilSOCl}_{2}\right)$ primary battery can be obtained. ${ }^{6}$ The obtained EIS data showed high degree of linearity and stability verified through Kramers-Kronig test. We have shown that the time constants obtained are related to the Solid Electrolyte Interface (SEI) formed at the surface of the $\mathrm{Li}$ anode and both anodic and cathodic charge transfer processes. It was shown that the applied DC-offset

${ }^{\text {zE} E-m a i l: ~ u l g u t @ f e n . b i l k e n t . e d u . t r ~}$ greatly influences the obtained impedance via changing the structure of the SEI. Previously, other studies implemented EIS measurements at open circuit potential and with potentiostatic excitations. The obtained data suffered from deviations at lower frequencies. Moreover, the linear data showed only one time constant at higher frequencies which is related to the SEI only and no time constants for the other electrochemical processes were revealed. ${ }^{7,8}$

In $\mathrm{Li} / \mathrm{SOCl}_{2}$ primary battery as shown in Fig. 2, the metallic $\mathrm{Li}$ anode reacts with the electrolyte Thionyl Chloride $\left(\mathrm{SOCl}_{2}\right)$ when in direct contact. The product is Lithium Chloride $(\mathrm{LiCl})$ which crystalizes and forms a passive layer at the surface of the Li known as Solid Electrolyte Interface (SEI). ${ }^{9,10}$ This layer continues to grow with storage time through proposed tunneling mechanisms. ${ }^{9,11}$ In operation, the layer is torn down by forming cracks allowing the migration of the $\mathrm{Li}^{+}$ions to react with the electrolyte $\mathrm{SOCl}_{2}$. These dynamic processes of formation/demolition have great effects on the battery's impedance and hence its voltage. Phenomena such as voltage delay and recovery are shown to be caused by the dynamic properties of the SEI. ${ }^{12}$

In this study, aiming at elucidating the EIS data and its correlation to the electrochemical processes of the $\mathrm{Li} / \mathrm{SOCl}_{2}$, we performed EIS analysis for $\mathrm{Li} / \mathrm{SOCl}_{2}$ reserve batteries with two electrolyte compositions. The first is made of $100 \% \mathrm{SOCl}_{2}$ electrolyte and the second of $75 \% \mathrm{SOCl}_{2}$ plus $25 \% \mathrm{SO}_{2} \mathrm{Cl}_{2}$ mixture of electrolytes. In both cells, all other components were identical. Through these variations in electrolyte, identification of the time constants in the $\mathrm{Li} / \mathrm{SOCl}_{2}$ cells with their Equivalent Circuit fits is shown.

\section{Experimental}

Cells.-Batteries tested in this study are $\mathrm{LilSOCl}_{2}$ reserve primary batteries produced by PILTEK Energy Systems Co. (Ostim Science Park, Ankara/Turkey) with model name 10-10-01 shown in Fig. 3a. Reserve batteries are special purpose primary batteries in which electrolyte is stored separately from the electrodes. Battery can be activated by breaking the ampoule storing the electrolyte. This floods the active cell compartment with electrolyte. Until the activation, battery remains inactive without any ion transfer between electrodes which eliminates capacity loss during shelf life. PILTEK 10-10-01 model reserve batteries are single cell type battery and liquid electrolyte is stored in breakable glass ampoule. Battery is activated by breaking the ampoule. Two reserve batteries were studied with identical components except for the electrolyte 

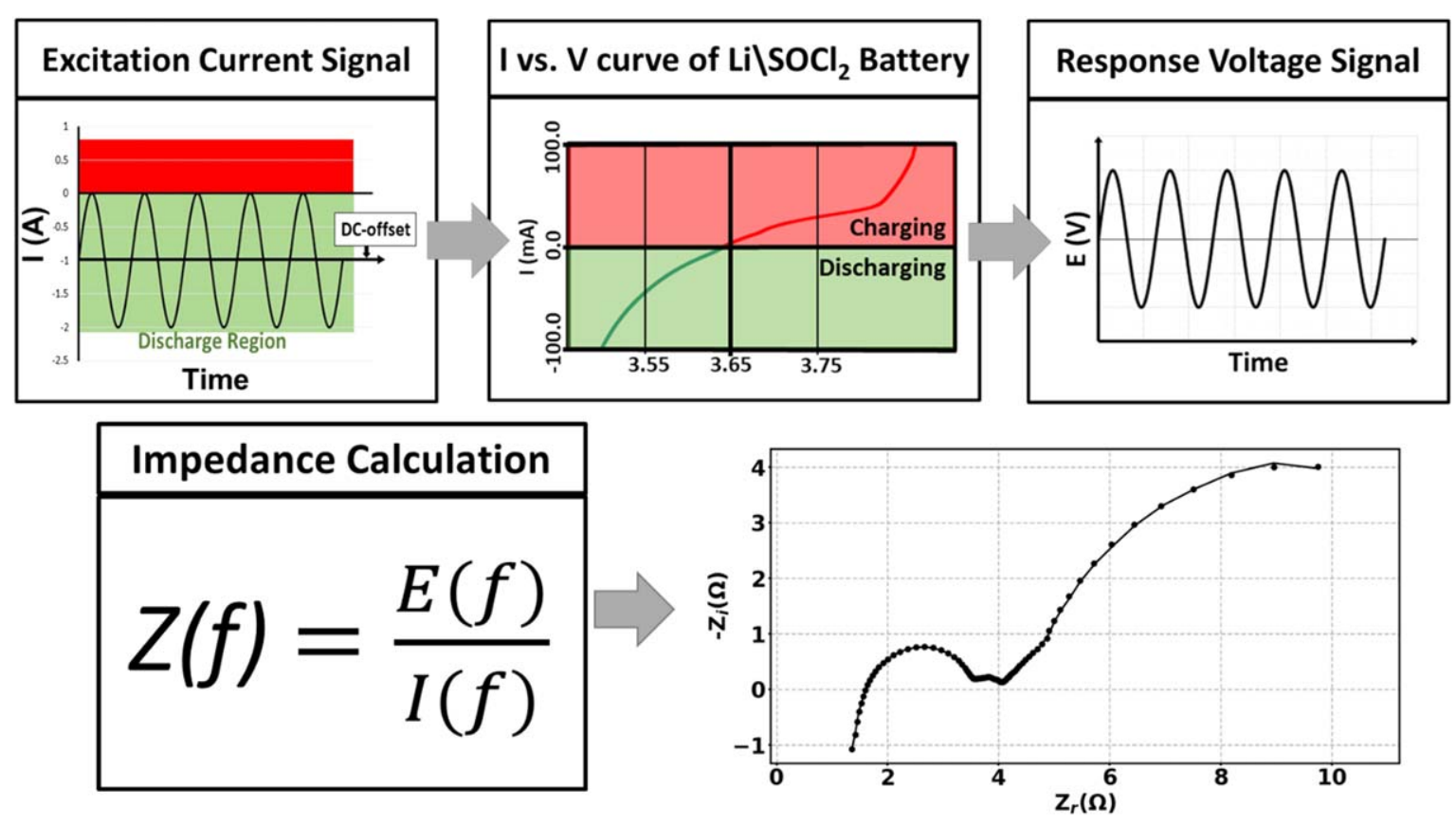

Figure 1. Galvanostatic-Electrochemical Impedance Spectroscopy at discharge technique applied for Lithium Thionyl $\mathrm{Chloride} \mathrm{Li} / \mathrm{SOCl}_{2}$ primary battery Excitation is achieved by Alternating Current signal on top of a negative Direct Current signal and the response is measured in voltage.

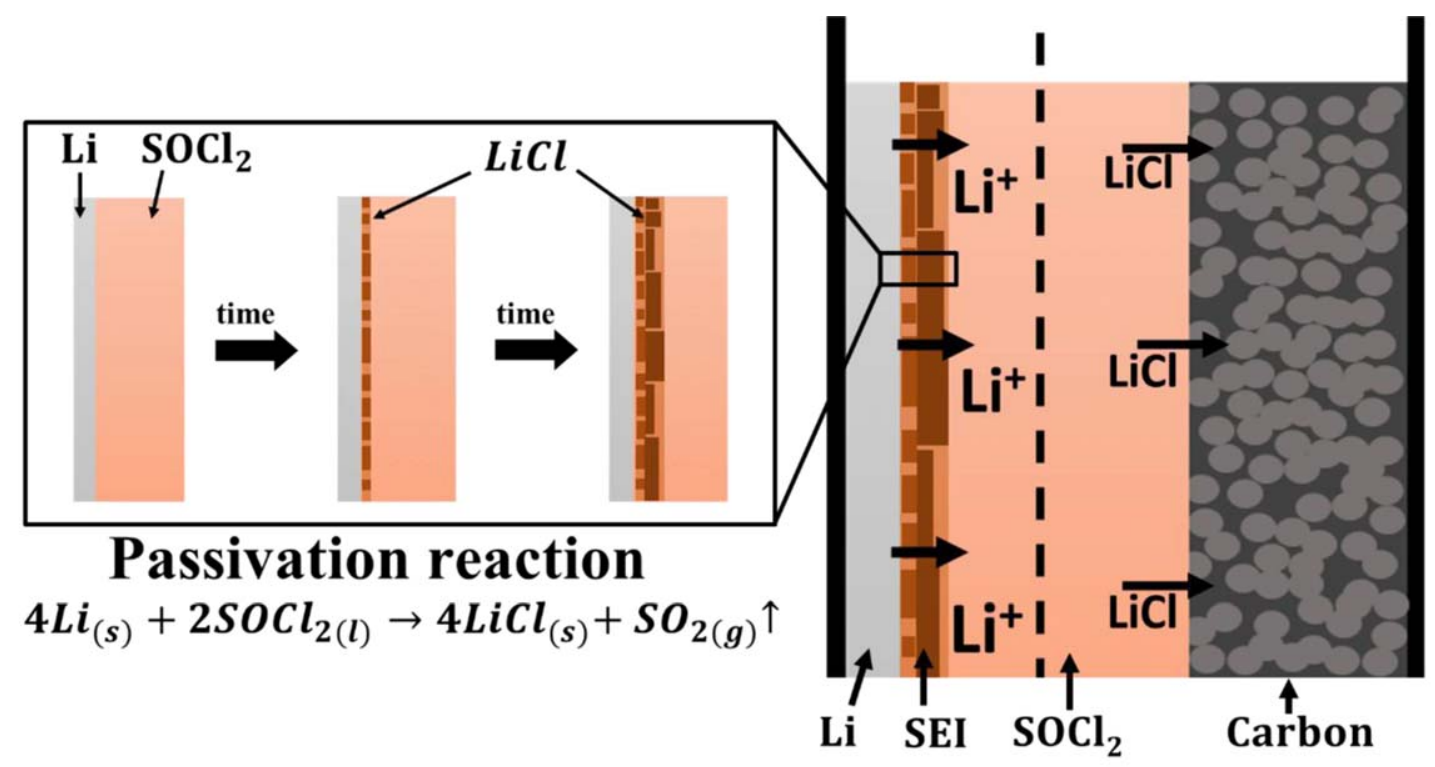

$$
\begin{array}{cl}
\mathrm{Li}_{(s)} \rightarrow \mathrm{Li}_{(\text {dis. })}^{+}+e^{-} & \begin{array}{l}
\text { Anode reaction } \\
\text { Cathode reaction }
\end{array} \\
\hline 4 \mathrm{Li}_{(\text {dis. })}^{+}+2 \mathrm{SOCl}_{2(l)}+4 e^{-} \rightarrow 4 \mathrm{LiCl}_{(s)}+\mathrm{SO}_{2(g)} \uparrow+S_{(s)} & \text { Overall reaction } \\
\hline 4 \mathrm{Li}_{(s)}+2 \mathrm{SOCl}_{2(l)} \rightarrow 4 \mathrm{LiCl}_{(s)}+\mathrm{SO}_{2(g)} \uparrow+S_{(s)} & \text { Nernst equation }
\end{array}
$$

Figure 2. Schematic of the structure of Lithium Thionyl Chloride Li/SOCl 2 primary battery and formation of the Solid Electrolyte Interface at the surface of the metallic Li by passivation reaction. The reactions at the anode, cathode and the resulting Nernst equation shows the stability of the cell' potential because of the reaction components unity activity and the escape of the $\mathrm{SO}_{2}$ gas from the cell. 

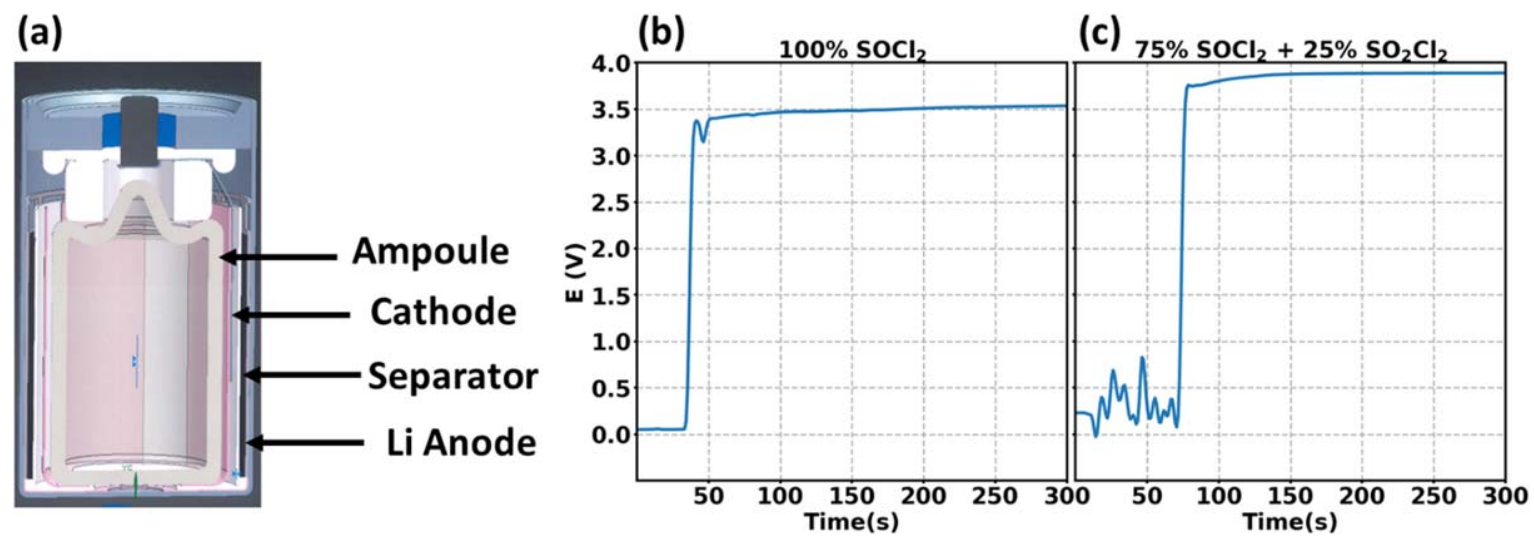

Figure 3. (a) Cross sectional view of PILTEK 10-10-01 model battery, representing ampoule, Lithium anode layer, separator and other supporting structures. Potential vs time plots for the reserve battery during activation for (b) $100 \% \mathrm{SOCl}_{2}$ electrolyte cell and (c) $75 \% \mathrm{SOCl}_{2} \mathrm{plus}_{25} \% \mathrm{SO}_{2} \mathrm{Cl}_{2}$ mixture electrolyte cell.

composition inside the ampoule. In the first cell, the electrolyte inside the ampule was filled with $100 \%$ Thionyl Chloride $\left(\mathrm{SOCl}_{2}\right)$. In the second cell, the electrolyte was filled with $75 \%$ Thionyl Chloride $\left(\mathrm{SOCl}_{2}\right)$ and $25 \%$ Sulfuryl Chloride $\left(\mathrm{SO}_{2} \mathrm{Cl}_{2}\right)$. For the measurement, activation of the cells was achieved by breaking the ampoule which resulted in a jump in the potential of the batteries which is shown in Figs. $3 b$ and $3 c$

Galvanostatic-electrochemical impedance spectroscopy at discharge.-Gamry Interface 5000E was used for the EIS measurements of the cells. EIS was measured at least $24 \mathrm{~h}$ after the activation of the reserve battery. This duration was necessary for the cells to reach equilibrium and for the open circuit potential to stabilize. After $24 \mathrm{~h}$, the open circuit potential for the $100 \% \mathrm{SOCl}_{2}$ cell was $3.65 \mathrm{~V}$ and for the $75 \% \mathrm{SOCl}_{2}$ plus $25 \% \mathrm{SO}_{2} \mathrm{Cl}_{2}$ cell was $3.86 \mathrm{~V}$. EIS was measured galvanostatically at discharge by excitation with Alternating Current (AC) signal on top of a negative Direct Current (DC) signal. The value of the AC and DC signals for $100 \%$ $\mathrm{SOCl}_{2}$ cell were $1 \mathrm{~mA} \mathrm{AC}$ and $-5 \mathrm{~mA} \mathrm{DC}$ and for the $75 \% \mathrm{SOCl}_{2}$ plus $25 \% \mathrm{SO}_{2} \mathrm{Cl}_{2}$ cell were $1 \mathrm{~mA} \mathrm{AC}$ and $-7 \mathrm{~mA}$ DC. These values were assigned by trial and error on bases of compatibility with Kramers-Kronig test. To achieve a more stable potential during the EIS measurement, the cells were discharged for $1 \mathrm{~min}$. with the same DC values applied at the EIS measurement. The frequency window for both cells was between $1 \mathrm{MHz}$ to $4 \mathrm{mHz}$ with 10 points measurement per decade. The obtained EIS data were tested for linearity and stability by Kramers-Kronig compatibility using the software Gamry Echem Analyst.

Equivalent circuit modeling.-Gamry Echem Analyst version 7.04 software was used to construct and fit the equivalent circuit models for the obtained EIS data.

\section{Results and Discussion}

EIS data for the $100 \% \mathrm{SOCl}_{2}$ electrolyte cell measured under two DC-offsets (low $=-1 \mathrm{~mA}$ and high $=-5 \mathrm{~mA}$ ) is shown in Fig. 4a. The blue points data is for the measurement done under low DCoffset in which the $\mathrm{Li}^{+}$ion transport through the SEI is hindered. The response for this process appears to have large impedance with large semicircle at the high frequency range and instable response after $100 \mathrm{~Hz}$. The red points data is for the same cell but with a high DC-offset measurement which shows a large decrease in the size of the high frequency semicircle. The decrease in the size can be correlated to the easing of $\mathrm{Li}^{+}$ion transport though the SEI.

It is also clear that other electrochemical phenomena related to the anode and cathode charge transfer are observed while it is not the case in the low DC-offset. The black curves in Fig. 4a denote the Kramers-Kronig compatibility of the data. It can be seen that the data for the low DC-offset is compatible at the high frequency range but gives unstable response after $100 \mathrm{~Hz}$. Though for the high DC offset data Kramers-Kronig is compatible for all the frequency range.

For $75 \% \mathrm{SOCl}_{2}+25 \% \mathrm{SO}_{2} \mathrm{Cl}_{2}$ electrolyte mixture cell, the EIS data are shown in Fig. 4b. Although the behavior is similar to the $100 \% \mathrm{SOCl}_{2}$, in which the SEI dominates the impedance response and hinders the kinetics of the cell, the shapes of the semicircles at the high frequency is different from $100 \% \mathrm{SOCl}_{2}$ cell. Here the SEI impedance show two overlapped semicircles indicating the presence of more than one layer. This two semicircles structure is present in both high and low DC-offset data.

Analysis of the electrochemical impedance spectroscopy.-For the analysis of the linear high DC-offset data, the overlay of the Kramers-Kronig transformable EIS of $100 \% \mathrm{SOCl}_{2}$ electrolyte and $75 \% \mathrm{SOCl}_{2}+25 \% \mathrm{SO}_{2} \mathrm{Cl}_{2}$ electrolyte cells is shown in Fig. 5. The main distinction is seen at the high frequency region, between $1 \mathrm{MHz}$ to $625 \mathrm{~Hz}$ for $100 \% \mathrm{SOCl}_{2}$ cell and $1 \mathrm{MHz}$ to $160 \mathrm{~Hz}$ for $75 \% \mathrm{SOCl}_{2}+25 \% \mathrm{SO}_{2} \mathrm{Cl}_{2}$ cell. The $100 \% \mathrm{SOCl}_{2}$ cell shows one semicircle indicating the presence of one time constant for charge transfer process or a coating layer whereas, the $75 \% \mathrm{SOCl}_{2}+25 \%$ $\mathrm{SO}_{2} \mathrm{Cl}_{2}$ cell shows two semicircles which shows the presence of two charge transfer processes or two layers.

In the literature, many EIS studies including our previous study for the EIS of the Li/SOCl${ }_{2}$, suggest that the high frequency time constants belong to the presence of the SEI. ${ }^{2,6}$ The data shown in Fig. 5 support this in which we expect one layer to form for the $100 \% \mathrm{SOCl}_{2}$ electrolyte and two layers for the $75 \% \mathrm{SOCl}_{2}+25 \%$ $\mathrm{SO}_{2} \mathrm{Cl}_{2}$ electrolyte. The two layers structure can be rationalized by the products formed from the reaction of the metallic $\mathrm{Li}$ with the electrolyte mixture. Spectroscopic studies suggest that the passivation reaction of the $\mathrm{Li}$ with $\mathrm{SOCl}_{2}$ forms $\mathrm{LiCl}$ crystals and $\mathrm{SO}_{2}$ gas as shown in Eq. $1 .^{13}$

$$
4 \mathrm{Li}_{(s)}+2 \mathrm{SOCl}_{(l)} \rightarrow 4 \mathrm{LiCl}_{(s)}+\mathrm{SO}_{2(g)}
$$

In the case of the passivation reaction of $\mathrm{Li}$ with $\mathrm{SO}_{2} \mathrm{Cl}_{2}$ the reaction is assigned to produce different products besides $\mathrm{LiCl}$. As shown in Eqs. 2 and 3 products such as $\mathrm{Li}_{2} \mathrm{~S}_{2} \mathrm{O}_{4}$ and $\mathrm{Li}_{2} \mathrm{SO}_{4}$ are detected at different rates. ${ }^{14}$ These products can be related to the formation of two layers in $75 \% \mathrm{SOCl}_{2}+25 \% \mathrm{SO}_{2} \mathrm{Cl}_{2}$ electrolyte cells.

$$
\begin{gathered}
6 \mathrm{Li}_{(s)}+2 \mathrm{SO}_{2} \mathrm{Cl}_{2(l)} \rightarrow 4 \mathrm{LiCl}_{(s)}+\mathrm{Li}_{2} \mathrm{~S}_{2} \mathrm{O}_{4(s)} \\
6 \mathrm{Li}_{(s)}+2 \mathrm{SO}_{2} \mathrm{Cl}_{2(l)} \rightarrow 4 \mathrm{LiCl}_{(s)}+\mathrm{Li}_{2} \mathrm{SO}_{4(s)}+\mathrm{S} .
\end{gathered}
$$

The other time constants in Fig. 5 show similar behavior in both cells with small semicircle at the middle frequency region between 
(a)

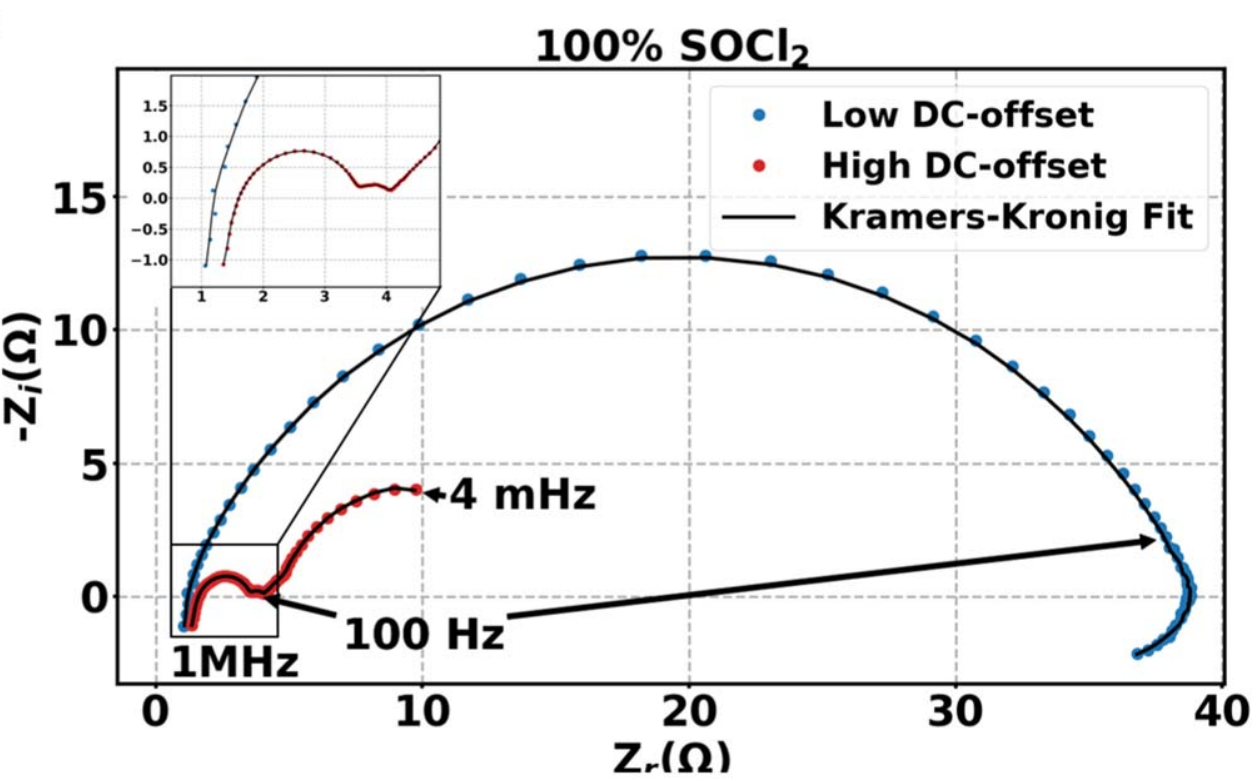

(b)

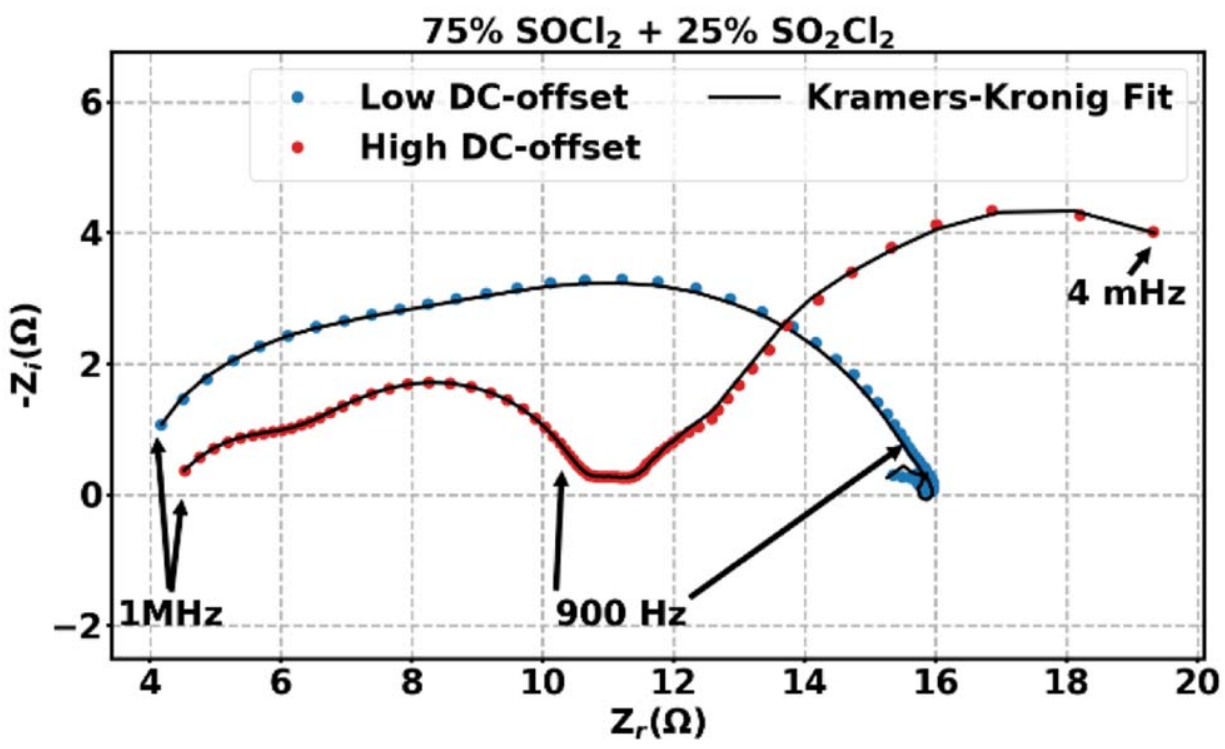

Figure 4. EIS Nyquist plots for the $\mathrm{Li} / \mathrm{SOCl}_{2}$ reserve batteries at low and high DC-offset values for (a) $100 \% \mathrm{SOCl}_{2}$ electrolyte with DC-offset values (low $=$ $-1 \mathrm{~mA}$ and high $=-5 \mathrm{~mA}$ ) and (b) $75 \% \mathrm{SOCl}_{2}+25 \% \mathrm{SO}_{2} \mathrm{Cl}_{2}$ electrolyte with DC-offset values (low $=-5 \mathrm{~mA}$ and high $=-7 \mathrm{~mA}$ ).

$650 \mathrm{~Hz}$ and $10 \mathrm{~Hz}$ for $100 \% \mathrm{SOCl}_{2}$ and $160 \mathrm{~Hz}$ to $5 \mathrm{~Hz}$ for $\mathrm{Li}_{2} \mathrm{~S}_{2} \mathrm{O}_{4}$ and $\mathrm{Li}_{2} \mathrm{SO}_{4}$ cell. This small semicircle can be related to the charge transfer at the Li anode (Li oxidation). The difference in frequencies can be related to the effect of the formed SEI on the charge transfer process at the anode. In the two layers structure the time constant appear at lower frequencies due to the high impedance of the SEI which slows down the anode reaction.

At the low frequency region both cells give identical response with two overlapping semicircles. The first is from $5 \mathrm{~Hz}$ to $80 \mathrm{mHz}$ which can be related to the cathodic reaction charge transfer. The second is from $80 \mathrm{mHz}$ to $4 \mathrm{mHz}$ showing the largest size among the other time constants which can be assigned to the adsorption of the reaction products $(\mathrm{LiCl})$ at the porous carbon which shows large capacitance and hence large $\mathrm{RC}$ time constant.

\section{Equivalent Circuit Analysis}

Equivalent Circuit (EC) analysis is performed for the obtained EIS to have better clarification for the time constants observed. Fig. $6 \mathrm{a}$ shows the EC fit for the $100 \% \mathrm{SOCl}_{2}$ cell and Fig. $6 \mathrm{~b}$ shows the fit for $75 \% \mathrm{SOCl}_{2}+25 \% \mathrm{SO}_{2} \mathrm{Cl}_{2}$ cell. For both cells Constant Phase Element (CPE) was used to fit the distorted semicircles which did not have ideal RC behavior. ${ }^{1}$

For the EC fits in our data each distorted semicircle was fit with a $\mathrm{CPE}$ connected in parallel with a resistor R(R//CPE). For $100 \%$ $\mathrm{SOCl}_{2}$ inductive behavior was observed at the highest frequencies which was fitted with an Inductor element L. At the highest frequency point a resistor was fitted to the data which corresponded to the electrolyte resistance $\mathrm{R}_{\mathrm{u}}$. The EC models used are shown in Fig. 6 and the fitted parameters for the two models are summarized in Table I.

For $100 \% \mathrm{SOCl}_{2}$, the data was fitted with an inductor, a solution resistance and five $\mathrm{R} / / \mathrm{CPE}$. The $\mathrm{CPEs}$ were assigned to the electrochemical processes as follows.

Solid electrolyte interphase.-The first two R//CPEs are assigned to the $\mathrm{Li}^{+}$transport through the SEI. The second $\mathrm{R} / / \mathrm{CPE}$ has five times larger resistance than the first one which is consistent with the proposed two layered structure model for the SEI. ${ }^{15}$ As proposed by previous studies the SEI has two layers with a compact thin 


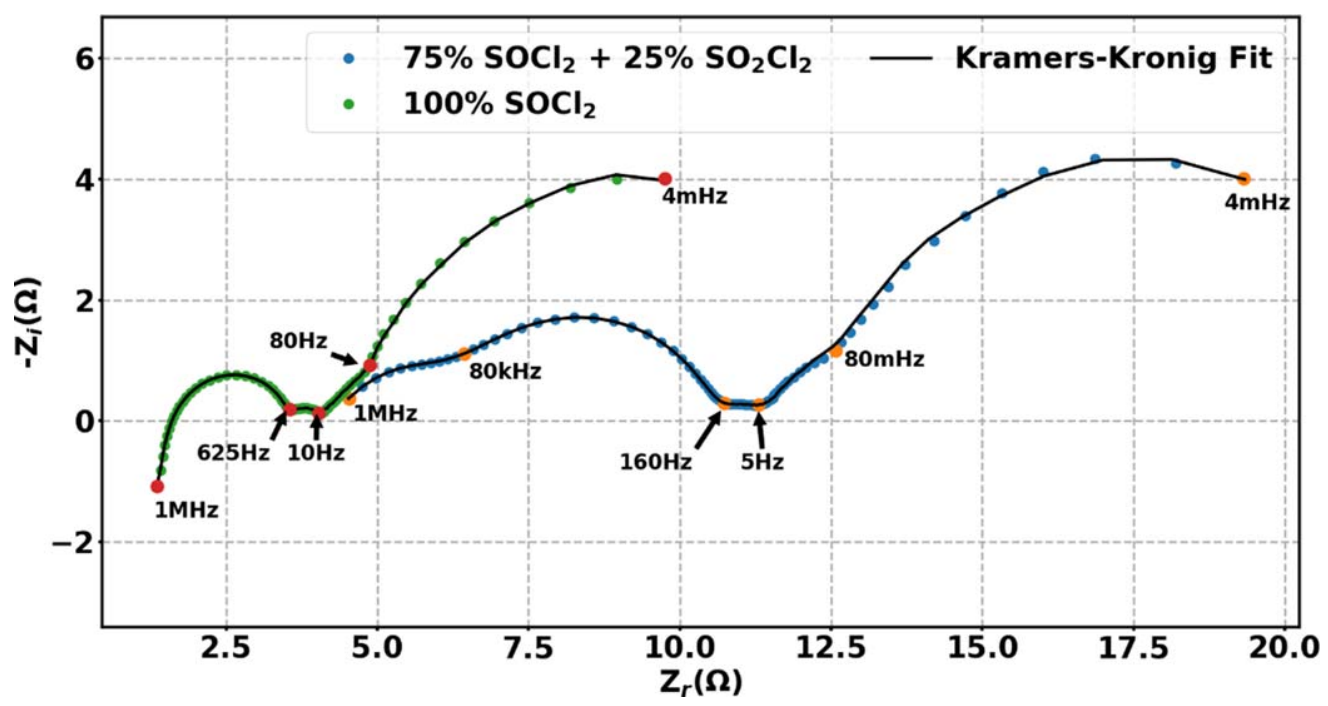

Figure 5. EIS Nyquist plots for the $\mathrm{Li} / \mathrm{SOCl}_{2}$ reserve batteries with different electrolyte compositions between $1 \mathrm{MHz}$ and $4 \mathrm{mHz}$ tested with $\mathrm{Kramers}-\mathrm{Kronig}$ compatibility.

Table I. Equivalent circuit parameters and their errors obtained from fitting the models shown in Fig. 6 for $100 \% \mathrm{SOCl}_{2}$ electrolyte cell and $75 \%$ $\mathrm{SOCl}_{2}+25 \% \mathrm{SO}_{2} \mathrm{Cl}_{2}$ electrolyte cell.

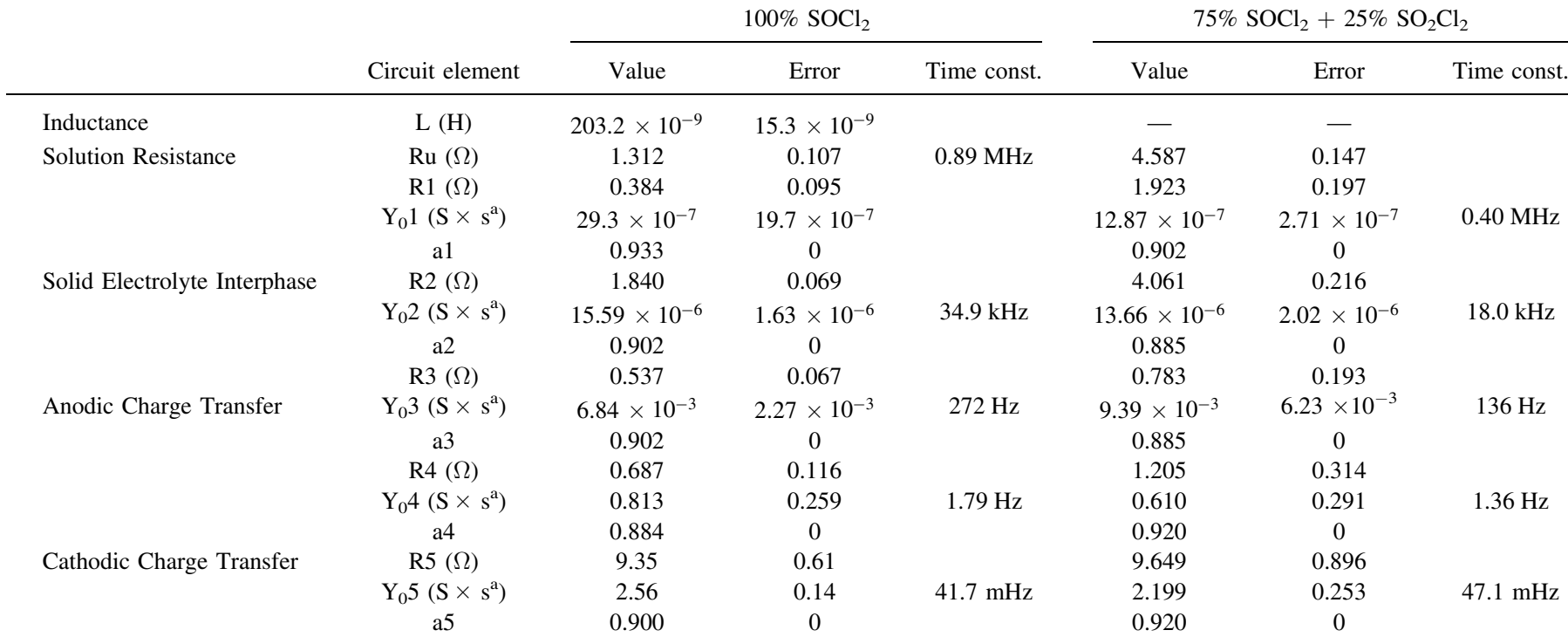

structure at the surface of the $\mathrm{Li}$ and a thick porous layer on top of the first layer. Our findings support these models with the obtained resistances.

Anodic charge transfer.- The third R//CPE was assigned to $\mathrm{Li}$ oxidation reaction which show low values of $\approx 0.5 \Omega$ and $6 \mathrm{mF}$.

Cathodic charge transfer and transport.-The last two R//CPEs can be assigned to the cathode reaction and the adsorption of the reaction products onto the porous carbon. The last $\mathrm{R} / / \mathrm{CPE}$ is assigned to the adsorption process because of its high capacitive value $\approx 2.5 \mathrm{~F}$ representing the adsorption onto the porous carbon while the other is to the reaction of $\mathrm{Li}^{+}$with $\mathrm{SOCl}_{2}$.

For $75 \% \mathrm{SOCl}_{2}+25 \% \mathrm{SO}_{2} \mathrm{Cl}_{2}$ cell the data are fitted with solution resistance at the highest frequency and five R//CPEs. The assignment of the electrochemical processes to the R//CPEs is the same as the $100 \% \mathrm{SOCl}_{2}$ cell with large variation in the time constants and the values of the first two R//CPEs belonging to the SEI.
The value of the resistance at the first $\mathrm{R} / / \mathrm{CPE}$ is five times larger than the $100 \% \mathrm{SOCl}_{2}$ cell indicating the presence of thicker layer. Likewise, the second $\mathrm{R} / / \mathrm{CPE}$ has two times the resistance compared to the $100 \% \mathrm{SOCl}_{2}$ cell. This increase in the resistances is correlated to what is mentioned previously regarding the formation of two layers from the different reaction products in the electrolyte mixture.

Comparing the time constants of the electrochemical processes in the two cells, we can observe the lower values of time constants for the $75 \% \mathrm{SOCl}_{2}+25 \% \mathrm{SO}_{2} \mathrm{Cl}_{2}$ cell for the first three $\mathrm{R} / / \mathrm{CPE}$ and the similar values for the last two. This indicates that the change in the electrolyte only effects the anodic charge transfer and the SEI processes which are related to the charge and mass transfer of the $\mathrm{Li}^{+}$. The time constants for the $\mathrm{Li}^{+}$transport through the SEI is slower in the mixture electrolyte cell and Li oxidation is also slowed down. The slow down at the anodic processes is related to the multicomponent two layers structure of the SEI formed as a result of the mixture of the electrolyte used. As the $\mathrm{Li}^{+}$is transported through the SEI the reaction with the electrolyte and the adsorption to the carbon has comparable rates in both cells. 
(a)
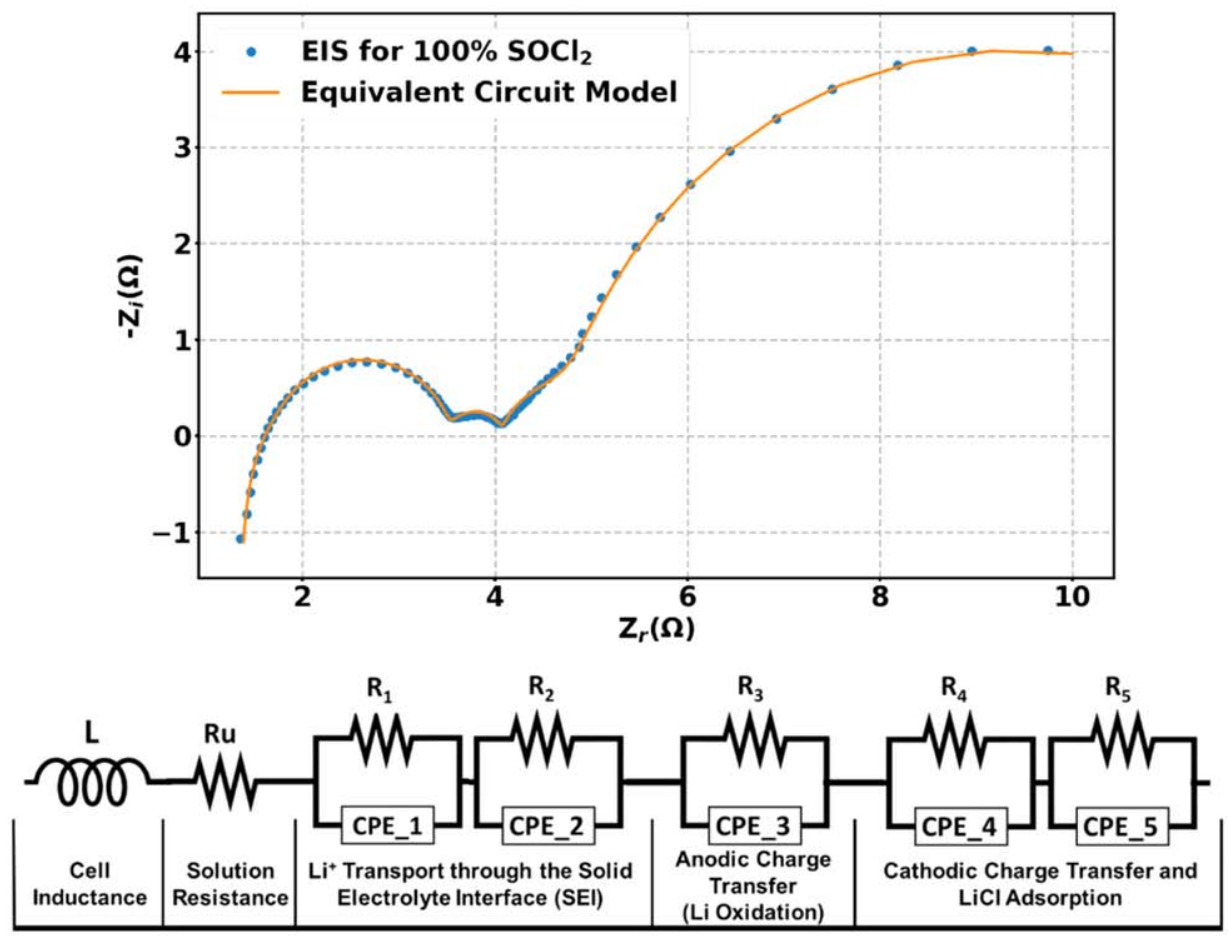

(b)
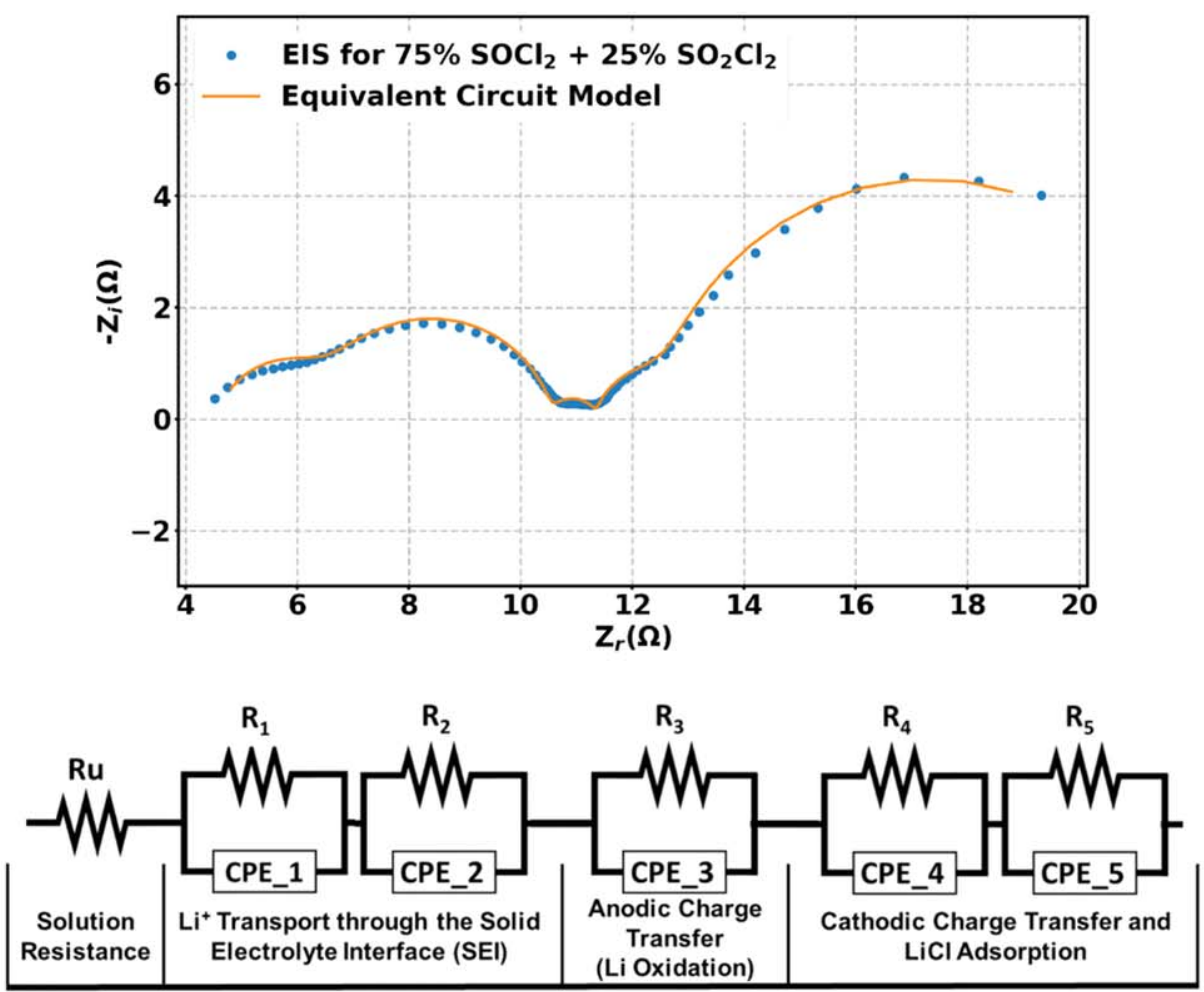

Figure 6. Equivalent Circuit fits overlayed with EIS Nyquist plots for the $\mathrm{Li} / \mathrm{SOCl}_{2}$ reserve batteries and the fitted equivalent circuit model for (a) $100 \%$ SOCl electrolyte cell and (b) $75 \% \mathrm{SOCl}_{2}+25 \% \mathrm{SO}_{2} \mathrm{Cl}_{2}$ electrolyte cell.

\section{Conclusions}

Characterization of different electrolyte composition Lithium Thionyl Chloride reserve primary batteries was done using Electrochemical Impedance Spectroscopy. The first cell had $100 \% \mathrm{SOCl}_{2}$ electrolyte and the second had $75 \% \mathrm{SOCl}_{2}+25 \% \mathrm{SO}_{2} \mathrm{Cl}_{2}$ mixture of electrolytes. Both cells showed similar EIS response with variations at the high frequency region. The $75 \% \mathrm{SOCl}_{2}+25 \% \mathrm{SO}_{2} \mathrm{Cl}_{2}$ cell showed two distorted semicircles while $75 \% \mathrm{SOCl}_{2}$ cell showed inductive behavior followed by one distorted semicircle at the very high frequency range $(1 \mathrm{MHz}-100 \mathrm{~Hz})$. This difference is related to the multi-component two layers structure of the SEI at the mixture electrolyte cell. Equivalent Circuit analysis using Constant Phase Element connected in parallel to a 
resistor for each distorted semicircle was performed. The obtained parameters for the first two semicircles at the high frequency region were related to the $\mathrm{Li}^{+}$transport through the SEI which had larger values for $75 \% \mathrm{SOCl}_{2}+25 \% \mathrm{SO}_{2} \mathrm{Cl}_{2}$ cell. The rest was assigned to the anodic and cathodic charge transfer processes with the largest semicircle assigned to the adsorption of the reaction products on the porous carbon. The charge transfer time constants showed slower responses for the mixture electrolyte cell. The obtained data and the performed analysis show the electrolyte composition effect in the formation of the SEI and hence the kinetics of the battery.

\section{ORCID}

Mohammed Ahmed Zabara (iD https://orcid.org/0000-0002-41956258

Burak Ulgut (D) https://orcid.org/0000-0002-4402-0033

\section{References}

1. M. E. Orazem and B. Tribollet, Electrochemical Impedance Spectroscopy (John Wiley \& Sons, Inc, Hoboken, NJ) (2008).

2. T. Osaka, D. Mukoyama, and H. Nara, "Review-development of diagnostic process for commercially available batteries, especially lithium ion battery, by electrochemical impedance spectroscopy." J. Electrochem. Soc., 162, A2529 (2015).

3. E. Barsoukov and J. R. Macdonald, Impedance Spectroscopy: Theory, Experiment, and Applications. (John Wiley \& Sons, Inc, Hoboken, NJ) (2005)
4. M. E. Orazem, J. M. Esteban, and O. C. Moghissi, "Practical applications of the kramers-kronig relations." Corrosion, 47, 248 (1991).

5. B. BOUKAMP, "Practical application of the Kramers-Kronig transformation on impedance measurements in solid state electrochemistry." Solid State Ionics, 62, 131 (1993).

6. M. A. Zabara, C. B. Uzundal, and B. Ulgut, "Linear and nonlinear electrochemica impedance spectroscopy studies of $\mathrm{Li} / \mathrm{SOCl}_{2}$ batteries." J. Electrochem. Soc., 166, A811 (2019).

7. M. Hughes, S. A. G. R. Karunathilaka, N. A. Hampson, and T. J. Sinclair, "The impedance of the lithium-thionyl chloride primary cell." J. Appl. Electrochem., 13, 669 (1983).

8. H.-Y. Hu and H.-W. Ko, "A.C. impedance studies on the lithium passivating layer of an $\mathrm{LiSOCl}_{2}$ cell." J. Power Sources, 26, 419 (1989).

9. G. Montesperelli, P. Nunziante, M. Pasquali, and G. Pistoia, "Li passivation in different electrolytes during storage and cycling - an impedance spectroscopy study." Solid State Ionics, 37, 149 (1990).

10. A. J. Hills and N. A. Hampson, "The LilSOCl 2 cell-a review." J. Power Sources, 24, 253 (1988)

11. J. Thevenin, "Passivating films on lithium electrodes. An approach by means of electrode impedance spectroscopy." J. Power Sources, 14, 45 (1985).

12. M. A. Zabara and B. Ulgut, "Electrochemical Impedance Spectroscopy based voltage modeling of lithium Thionyl Chloride $(\mathrm{Li} / \mathrm{SOCl} 2)$ primary battery at arbitrary discharge." Electrochim. Acta, 334, 135584 (2020).

13. S. Dallek, "Exothermic reactions among components of lithium-sulfur dioxide and lithium-thionyl chloride cells." J. Electrochem. Soc., 128, 508 (1981).

14. G. Razzini et al., "The lithium-sulfuryl chloride battery: discharge behaviour." J. Power Sources, 5, 263 (1980).

15. M. B. Mogensen and E. Hennes $\varnothing$, "Properties and structure of the LiCl-films on lithium anodes in liquid cathodes." Acta Chimica Slovenica, 63, 519 (2016). 